\title{
Perceived Stigma and Associated Factors among Patient with Tuberculosis, Wolaita Sodo, Ethiopia: Cross-Sectional Study
}

\author{
Bereket Duko (iD, ${ }^{1}$ Asres Bedaso $(\mathbb{D}),{ }^{1}$ Getinet Ayano, ${ }^{2}$ and Zegeye Yohannis ${ }^{2}$ \\ ${ }^{1}$ Faculty of Health Sciences, College of Medicine and Health Sciences, P.O. Box 1560, Hawassa University, Hawassa, Ethiopia \\ ${ }^{2}$ Research and Training Directorate, Amanuel Mental Specialized Hospital, Addis Ababa, Ethiopia \\ Correspondence should be addressed to Bereket Duko; berkole.dad@gmail.com
}

Received 15 January 2019; Revised 12 March 2019; Accepted 3 April 2019; Published 2 May 2019

Academic Editor: Vincent Jarlier

Copyright (C) 2019 Bereket Duko et al. This is an open access article distributed under the Creative Commons Attribution License, which permits unrestricted use, distribution, and reproduction in any medium, provided the original work is properly cited.

Background. Tuberculosis is a historically stigmatized disease and the stigma associated with it affects the institution, community, and interpersonal factors. Therefore, understanding tuberculosis-related perceived stigma has importance in improving quality of the patients. Objective. The aim of this study was to assess prevalence and factors associated with perceived stigma among patients with tuberculosis attending Wolaita Sodo University Referral Hospital, Ethiopia. Methods. Institution based cross-sectional study was conducted among a total of 417 tuberculosis patients who had treatment follow-up at TB clinics and were recruited for the study. Systematic random sampling technique was used to recruit study participants. A 12 -item perceived TB stigma scale was used to assess tuberculosis-related perceived stigma. In addition, Oslo social support scale was used to assess social support related factors. Results. Prevalence of tuberculosis-related perceived stigma by using perceived tuberculosis stigma scale was $42.4 \%$. Patients who had pulmonary TB $[\mathrm{AOR}=2.49,(95 \% \mathrm{CI}: 1.24,4.87)]$, being intensive phase category $[\mathrm{AOR}=1.42,(95 \% \mathrm{CI}: 1.19,2.58)]$, TB/HIV coinfection $[\mathrm{AOR}=3.54,(95 \% \mathrm{CI}: 1.37,9.12)]$, poor social support $[\mathrm{AOR}=2.45$, (95\% CI: 1.18, 5.09)], and using substance (alcohol, khat and cigarette) $[\mathrm{AOR}=1.78,(95 \% \mathrm{CI}: 1.28,3.17)]$ were more likely to have perceived TB stigma when compared to their counter parts. Conclusion. Health education programs should be conducted to reduce TB stigma and improve patients' compliance.

\section{Introduction}

Tuberculosis (TB) is one of chronic infectious disease which is caused by Mycobacterium tuberculosis and becomes the leading causes of morbidity and mortality worldwide $[1,2]$. It is a key public health concern in Ethiopia: in 2009/2010, it was the second most important cause of death [3]. Ethiopia is ranked seventh among the 22 high-burden countries that account for $81 \%$ of all cases of TB and $80 \%$ of all TB deaths worldwide [4]. Ethiopia is also one of the 27 countries identified as having a high prevalence of multidrug-resistant TB (MDR-TB). The burden of MDR-TB in these countries accounts for $86 \%$ of cases worldwide $[3,5]$.

Stigma stands as decreasing attribute which arises from social interaction and is related to the power dominance and difference [6]. Social (enacted) stigma refers to experience discrimination by other people which results from inferiority in the society while perceived stigma refers to the shame and expectation of discrimination that prevents people from talking about their experiences and sense of unworthy and guilty [7-19]. TB is highly stigmatized disease which can be experienced and felt at a different social setting like home, workplace, and community [7].

Perceived stigma has a considerable impact on health that renders patients to refuse disease and medical services through discouraging health-seeking behavior which leads to distortion of health condition making difficult to treat that increases infectivity and communicability of the disease [713]. It is more common in patients with tuberculosis. Some studies conducted in Egypt Chest Hospital and in southern Thailand and Nepal showed that the prevalence of perceived stigma was $41.5 \%$ and $63.3 \%$, respectively [20-22].

Therefore, understanding tuberculosis-related perceived stigma has importance in improving the quality of these 
populations. Therefore, this aimed to assess prevalence and associated factors of perceived stigma among TB patients in Ethiopia.

\section{Methods}

2.1. Study Setting and Population. Institution based crosssectional study design was conducted from March 2016 to May 2016 at Wolaita Sodo University Referal Hospital, Woliata Sodo, Ethiopia. Tuberculosis patients whose ages were $\geq 18$ years were included in the study, while critically ill patients were excluded from the study. Single population proportion formula was used to get the required sample size. Because there was no prior study on the subject area, to get maximum sample size we used prevalence of perceived TB stigma as $50 \%(\mathrm{P}=50 \%), 95 \% \mathrm{CI}$, margin error of $5 \%$, and $10 \%$ none-response rate; the required sample size became 424. Seven patients were excluded from the study due to critical condition of the illness. Among tuberculosis patients who had treatment follow-up TB clinics during the study period in the mentioned hospital, we had recruited 417 tuberculosis patients. Systematic random sampling technique was employed to select the study participants.

2.2. Data Collection. Our data collection instruments had included a structured interviewer administered questionnaires on sociodemographic characteristic which mainly focuses on age, sex, education, occupation, marital status, religious view of the study participants, and others. We have also used Oslo item 3 social support scales which is 3-item questionnaire commonly used to assess social support related issues in clinical and community settings [23]. The variable of interest (outcome variable), TB stigma felt by TB patients, was collected by 12 -item perceived TB stigma scale that consisted of four-point Likert scale questions concerning perceived isolation, guilt, shame, and disclosure of their tuberculosis status. It was validated in Thailand among TB and HIV patients; its goodness-of-fit was good (TLI $=94$, LFI = 0.88 , and RMSEA $=0.11$ ), internal consistency was excellent (Cronbach's alphas 0.82-0.91), and test-retest reliability was moderate. It has good psychometric properties that measure stigma associated with tuberculosis and HIV/AIDS and allow assessment of stigma from community and patient perspectives. Participants were classified as having or not having perceived stigma using the mean of the stigma variable as cut-off point [21]. This scale was adopted and translated to Amharic language and it was highly reliable in the study with Cronbach's $\alpha$ of 0.95 .

2.3. Data Processing and Analyses. We used SPSS version 22 to analyze the data. The association of each independent variable with perceived tuberculosis stigma was examined in bivariate analysis. Those confounding variables that could potentially be associated with both TB and perceived stigma like anxiety, depression, substance use, social support, and other variables with $\mathrm{p}$ value less than 0.2 during bivariate analysis were entered into the multivariate analysis to identify potential confounders. A p value of less than 0.05 was considered statistically significant, and adjusted odds ratio with $95 \%$ CI was calculated to determine association.

\section{Results}

3.1. Sociodemographic Characteristics of the Study Participants. The study recruited a total of 417 tuberculosis patients; the mean $( \pm S D)$ age of the respondents was 32.3 years $( \pm 9.23)$. Concerning sociodemographic characteristics, 241 (57.8\%) were male, 189 (45.3\%) were from protestant religious background, and 199 (47.7\%) were never married. In addition, 287 $(68.8 \%)$ patients were diagnosed with pulmonary TB, 270 $(64.9 \%)$ were in intensive phase of TB treatment, and 229 (54.9\%) had good social support (Table 1 ).

\subsection{Prevalence of Perceived Stigma and Associated Factors} among the Study Participants. Prevalence of tuberculosisrelated perceived stigma by using Perceived Tuberculosis stigma scale was $42.4 \%$. Prevalence of isolation, guilt, disclosure, and their relationship to social support is 42.4 $\%$, 37.9\%, $40.1 \%$, and $36.6 \%$, respectively. Using of binary logistic regression analysis revealed that having pulmonary TB $(\mathrm{AOR}=2.49, \mathrm{CI}:(1.24,4.87),(\mathrm{P}<0.01))$, being in intensive phase of tuberculosis treatment $(\mathrm{AOR}=1.42, \mathrm{CI}:(1.19,2.58)$, $(\mathrm{P}=0.02))$, having comorbid HIV illness (AOR=3.54, CI:(1.37, 9.12), $(\mathrm{P}<0.01))$, having poor social support $(\mathrm{AOR}=2.45, \mathrm{CI}$ : $(1.18,5.09)(\mathrm{P}<0.01))$, and current substance use $(\mathrm{AOR}=1.78$, CI:(1.28, 3.17), $(\mathrm{P}=0.01))$ (Table 2).

\section{Discussion}

Prevalence of TB related perceived stigma in the current study was $42.4 \%$ (95\%, CI: 39.28-45.52). This finding is in agreement with study conducted in Egypt Chest Hospital and southern Thailand [20, 21]. Nevertheless, a study result was lower than study conducted in Nepal [22]. This difference might be related to variation in study design, data collection tool, sample size, and study participant's variation. The difference also attributed due to variation in culture which is supported by findings from a systematic review and other studies that revealed cultural variations is potential for stigma [24-26].

Perceived stigma was mostly prevalent in patients with pulmonary tuberculosis when compared to those who had extra pulmonary tuberculosis. In addition to this, there was significant association between TB related perceived stigma and intensive phase of treatment. This finding is in agreement with the other study [22]. TB related perceived stigma is often a product of exaggerated notions of contagiousness. Community awareness and patient education may help to mitigate the isolation and rejection of $\mathrm{TB}$ patients and encourage TB suspects to seek initial care.

Tuberculosis patients who had comorbid HIV infection were more likely to have perceived stigma. This might be evidenced by having diagnosed with HIV illness by itself associated with high levels of stigma. Hence, TB/HIV coinfected patients can be at higher risk of having perceived stigma $[27,28]$. 
TABLE 1: Sociodemographic and clinical characteristics of TB patients on follow-up at Wolaita Sodo University Hospital, Wolaita Sodo, Ethiopia, 2016.

\begin{tabular}{|c|c|c|c|}
\hline Variables & & Frequency & Percent (\%) \\
\hline \multirow[t]{3}{*}{ Age } & $18-24$ years & 96 & 21 \\
\hline & $25-49$ years & 226 & 70 \\
\hline & $>=50$ years & 38 & 9 \\
\hline \multirow[t]{2}{*}{ Sex } & Male & 241 & 58 \\
\hline & Female & 176 & 42 \\
\hline \multirow[t]{3}{*}{ Marital status } & Married & 182 & 44 \\
\hline & Single & 199 & 48 \\
\hline & Divorced/Widowed & 66 & 9 \\
\hline \multirow[t]{4}{*}{ Education status } & No formal education & 78 & 19 \\
\hline & Grade 1-8 & 129 & 31 \\
\hline & Grade 9-12 & 116 & 28 \\
\hline & College and above & 94 & 23 \\
\hline \multirow{3}{*}{ Duration of illness } & $<6$ months & 25 & 6 \\
\hline & $6-12$ months & 247 & 59 \\
\hline & $>=12$ months & 145 & 35 \\
\hline \multirow[t]{2}{*}{ Phase of treatment } & Intensive phase & 270 & 65 \\
\hline & Continuation phase & 147 & 35 \\
\hline \multirow{3}{*}{ Co-morbid chronic illness } & HIV/AIDS & 49 & 12 \\
\hline & Diabetes/Hypertension & 24 & 6 \\
\hline & No co-morbid illness & 344 & 83 \\
\hline \multirow[t]{2}{*}{ Social support } & Good & 229 & 55 \\
\hline & Poor & 188 & 45 \\
\hline \multirow[t]{2}{*}{ Depressive symptoms } & Yes & 181 & 43 \\
\hline & No & 236 & 57 \\
\hline \multirow[t]{2}{*}{ Anxiety symptoms } & Yes & 173 & 41 \\
\hline & No & 244 & 59 \\
\hline \multirow[t]{2}{*}{ Substance (khat, cigarette \& alcohol) use } & Yes & 30 & 7 \\
\hline & No & 387 & 93 \\
\hline
\end{tabular}

TABLE 2: Factors associated with TB related perceived stigma among patients with TB at Wolaita Sodo University Referral Hospital, Wolaita Sodo, Ethiopia, 2016, $\mathrm{n}=417$.

\begin{tabular}{|c|c|c|c|c|c|}
\hline \multirow{2}{*}{ Explanatory Variables } & & \multicolumn{2}{|c|}{ Perceived TB stigma } & \multirow{2}{*}{ COR,95\% (CI) } & \multirow{2}{*}{ AOR,95\% (CI) } \\
\hline & & Yes & No & & \\
\hline \multirow{3}{*}{ Age } & $18-24$ & 23 & 65 & $0.21,(0.09,1.47)$ & \\
\hline & $25-49$ & 130 & 161 & $0.47,(0.23,1.03)$ & \\
\hline & 50 and above & 24 & 14 & 1 & 1 \\
\hline \multirow{2}{*}{ Sex } & Male & 96 & 145 & 1 & 1 \\
\hline & Female & 81 & 95 & $1.29,(1.09,2.97)$ & \\
\hline \multirow{4}{*}{ Educational status } & No formal education & 45 & 33 & $1.97,(1.07,3.63)$ & \\
\hline & Grade 1-8 & 48 & 81 & $0.84,(0.50,1.48)$ & \\
\hline & Grade 9-12 & 45 & 71 & $0.94,(0.54,1.63)$ & \\
\hline & College and above & 39 & 55 & 1 & 1 \\
\hline \multirow{6}{*}{ Job } & Civil servant & 33 & 43 & 1 & 1 \\
\hline & Non-governmental & 33 & 52 & $1.59,(0.84,2.99)$ & \\
\hline & Merchant & 23 & 28 & $1.31,(0.71,2.41)$ & \\
\hline & Farmer & 8 & 7 & $1.70,(0.84,3.45)$ & \\
\hline & House wives & 27 & 25 & $2.37,(0.78,7.15)$ & \\
\hline & Jobless/Daily labors & 29 & 60 & $4.35,(2.08,8.11)$ & \\
\hline \multirow{2}{*}{ Classification } & Pulmonary TB & 147 & 140 & $3.50,(2.19,5.56)$ & $2.49,(1.24,4.87) * *$ \\
\hline & Extra pulmonary TB & 30 & 100 & 1 & 1 \\
\hline \multirow{2}{*}{ Phase of treatment } & Intensive phase & 75 & 134 & $1.97,(1.29,4.56)$ & $1.42,(1.19,2.58) *$ \\
\hline & Continuous phase & 102 & 106 & 1 & 1 \\
\hline \multirow{3}{*}{ Co-morbid chronic illness } & HIV/AIDS & 36 & 13 & $4.85,(2.48,9.49)$ & $3.54,(1.37,9.12) * *$ \\
\hline & Diabetes/Hypertension & 16 & 8 & $3.50,(1.45,8.42)$ & \\
\hline & No chronic illness & 177 & 219 & 1 & 1 \\
\hline \multirow{2}{*}{ Social support } & Good & 42 & 187 & 1 & 1 \\
\hline & Poor & 135 & 53 & $11.34,(7.15,17.99)$ & $2.45,(1.18,5.09) * *$ \\
\hline \multirow{2}{*}{ Substance (Cigarette, khat and alcohol) use } & Yes & 51 & 28 & $2.87,(2.12,4.18)$ & $1.78,(1.28,3.17) *$ \\
\hline & No & 131 & 207 & 1 & 1 \\
\hline
\end{tabular}


The study also showed that those patients who had poor social support were significantly associated with perceived stigma. Having poor social support and somatic illness may lead to increased psychological distress [29]. Tuberculosis patients who had family history of mental illness were more likely to have perceived stigma. This finding was consistent with other findings $[20,30]$. This might be due to the fact that anxious patients are more prone to use substances like alcohol and cigarette to relief themselves from the internalized stigma.

Study conducted in Nigeria among patients with pulmonary tuberculosis showed that no formal education and patients who are in the working age group of 20 to 50 years had perceived TB stigma. Nevertheless, in this study there is no statistically significant association.

\section{Conclusion}

Prevalence of Tuberculosis-related perceived stigma by using perceived tuberculosis stigma scale was high (42.4\%). Having pulmonary $\mathrm{TB}$, being in intensive phase of tuberculosis treatment, having comorbid HIV illness, having poor social support, and using substances like alcohol and cigarette were associated with perceived stigma. Health professionals who are working TB clinics should give more emphasis to their patients and giving psychosocial counseling daily basis is recommended. Health education programs should be conducted to reduce TB stigma and improve patients' compliance.

\section{Limitation of the Study}

This study did not do detailed validation study for perceived HIV related-stigma scale and Oslo 3-item social support scale. We did not include BMI in our assessment.

\section{Data Availability}

The data used to support the findings of this study are included within the article.

\section{Ethical Approval}

Ethical clearance for this study was obtained from the Research and Ethics Review Committee of College of Medicine and Health Sciences, Gondar University and Amanuel Mental Specialized Hospital. Permission letter was obtained and submitted to Wolaita Sodo University Referral Hospital. Study participants were informed about their rights to interrupt the interview at any time and written informed consent was obtained from each study participants. Confidentiality was maintained at all levels of the study. TB patients were found to have TB related perceived stigmas referred to psychiatry clinics for further psychosocial counseling and support.

\section{Conflicts of Interest}

The authors declare that they have no conflicts of interest.

\section{Authors' Contributions}

Bereket Duko conceived the study and was involved in the study design, reviewed the article analysis, and was involved in report writing. Asres Bedaso, Getinet Ayano, and Zegeye Yohannis were involved in the study design and reviewing in articles. Bereket Duko drafted the manuscript. All authors read and approved the final manuscript.

\section{Acknowledgments}

The authors appreciate the respective study institution for their help and the study participants for their cooperation in providing all necessary information.

\section{References}

[1] P. M. Small, "Tuberculosis research," Journal of the American Medical Association, vol. 276, no. 18, pp. 1512-1513, 1996.

[2] R. Rajeswari, R. Balasubramanian, M. Muniyandi, S. Geetharamani, and X. Thresa, "Socio-economic impact of tuberculosis on patients and family in India," International Journal of Tuberculosis and Lung Disease, vol. 3, pp. 869-877, 2009.

[3] Federal Ministry of Health of Ethiopia, Guidelines for Clinical and Programmatic Managment of TB, Leprosy and TB/HIV in Ethiopia, Falcon Printing, Addis Ababa, Ethiopia, 5th edition, 2012.

[4] World Health Organization, Global Tuberculosis Control, WHO Report, Geneva, Switzerland, 2013, http://www.who.int/tb/ publications/.

[5] WHO, "Global tuberculosis control report," 2011.

[6] E. A. Dodor, K. Neal, and S. Kelly, "An exploration of the causes of tuberculosis stigma in an urban district in Ghana," The International Journal of Tuberculosis and Lung Disease, vol. 12, no. 9, pp. 1048-1054, 2008.

[7] A. Kurspahic-Mujcic, A. Hasanovic, and S. Sivic, "Tuberculosis related stigmaand delay in seeking care after the onset of symptoms associated with tuberculosis," Medicinski Glasnik (Zenica), vol. 10, no. 2, pp. 272-277, 2013.

[8] F. A. Khalid, E. A. Frah, A. Osman, and T. Abdlhameed, "Stigma towards Tuberculosis patients in Kassala, Sudan," International Journal of Research, vol. 1, no. 5, pp. 794-800, 2014.

[9] A. Courtwright and A. N. Turner, "Tuberculosis and stigmatization: Pathways and interventions," Public Health Reports, vol. 125, no. 4, pp. 34-42, 2010.

[10] J. Macq, A. Solis, G. Martinez, and P. Martiny, "Tackling tuberculosis patients' internalized social stigma through patient centred care: An intervention study in rural Nicaragua," $B M C$ Public Health, vol. 8, no. 1, p. 154, 2008.

[11] S. C. Baral, D. K. Karki, and J. N. Newell, "Causes of stigma and discrimination associated with tuberculosis in Nepal: A qualitative study," BMC Public Health, vol. 7, no. 1, p. 211, 2007.

[12] A. M. Kipp, P. Pungrassami, P. W. Stewart, V. Chongsuvivatwong, R. P. Strauss, and A. Van Rie, "Study of tuberculosis and AIDS stigma as barriers to tuberculosis treatment adherence using validated stigma scales," The International Journal of Tuberculosis and Lung Disease, vol. 15, no. 11, pp. 1540-1545, 2011.

[13] E. Goffman, Stigma, Notes on the Management of Spoiled Identity, Anchor Books, Garden City, NY, USA, 1963. 
[14] R. Smith, K. Rossetto, and B. L. Peterson, "A meta-analysis of disclosure of one's HIV-positive status, stigma and social support," AIDS Care, vol. 20, no. 10, pp. 1266-1275, 2008.

[15] P. Y. Collins, H. von Unger, and A. Armbrister, "Church ladies, good girls, and locas: Stigma and the intersection of gender, ethnicity, mental illness, and sexuality in relation to HIV risk," Social Science \& Medicine, vol. 67, no. 3, pp. 389-397, 2008.

[16] H. Deacon, "Towards a sustainable theory of health-related stigma: lessons from the HIV/AIDS literature," Journal of Community \& Applied Social Psychology, vol. 16, no. 6, pp. 418425, 2006.

[17] A. M. Courtwright, "Justice, stigma, and the new epidemiology of health disparities," Bioethics, vol. 23, no. 2, pp. 90-96, 2009.

[18] B. Major and L. T. O’Brien, “The social psychology of stigma," Annual Review of Psychology, vol. 56, pp. 393-421, 2005.

[19] R. Parker and P. Aggleton, "HIV and AIDS-related stigma and discrimination: a conceptual framework and implications for action," Social Science \& Medicine, vol. 57, no. 1, pp. 13-24, 2003.

[20] N. A. Eldahshan, R. A. Mohamed, and R. F. Abdellah, "Assessment of TB stigma among patients attending chest hospital in Suez Canal University area, Egypt," World Family Medicine Journal/Middle East Journal of Family Medicine, vol. 13, no. 5, pp. 21-28, 2015.

[21] A. van Rie, S. Sengupta, P. Pungrassami et al., "Measuring stigma associated with tuberculosis and HIV/AIDS in southern Thailand: exploratory and confirmatory factor analyses of two new scales," Tropical Medicine \& International Health, vol. 13, no. 1, pp. 21-30, 2008.

[22] S. Aryal, A. Badhu, S. Pandey et al., "Stigma related to tuberculosis among patients attending DOTS clinics of Dharan Municipality," Kathmandu University Medical Journal, vol. 10, no. 37, pp. 48-52, 2012.

[23] O. S. Dalgard, C. Dowrick, V. Lehtinen et al., "Negative life events, social support and gender difference in depression," Social Psychiatry and Psychiatric Epidemiology, vol. 41, no. 6, pp. 444-451, 2006.

[24] S.-H. Chang and J. K. Cataldo, "A systematic review of global cultural variations in knowledge, attitudes and health responses to tuberculosis stigma," The International Journal of Tuberculosis and Lung Disease, vol. 18, no. 2, pp. 168-173, 2014.

[25] L. V. Adams, D. Basu, S. W. Grande et al., "Barriers to tuberculosis care delivery among miners and their families in South Africa: An ethnographic study," The International Journal of Tuberculosis and Lung Disease, vol. 21, no. 5, pp. 571-578, 2017.

[26] N. Juniarti and D. Evans, "A qualitative review: the stigma of tuberculosis," Journal of Clinical Nursing, vol. 20, no. 13-14, pp. 1961-1970, 2011.

[27] K. Peltzer, P. Naidoo, G. Matseke, J. Louw, G. Mchunu, and B. Tutshana, "Prevalence of psychological distress and associated factors in tuberculosis patients in public primary care clinics in South Africa," BMC Psychiatry, vol. 12, p. 89, 2012.

[28] L. Li, S.-J. Lee, P. Thammawijaya, C. Jiraphongsa, and M. J. Rotheram-Borus, "Stigma, social support, and depression among people living with HIV in Thailand," AIDS Care Psychological and Socio-medical Aspects of AIDS/HIV, vol. 21, no. 8, pp. 1007-1013, 2009.

[29] H. Bøen, O. S. Dalgard, R. Johansen, and E. Nord, "Sociodemographic, psychosocial and health characteristics of Norwegian senior centre users: A cross-sectional study," Scandinavian Journal of Public Health, vol. 38, no. 5, pp. 508-517, 2010.
[30] I. A. Abioye, M. O. Omotayo, and W. Alakija, "Sociodemographic determinants of stigma among patients with pulmonary tuberculosis in Lagos, Nigeria," African Health Sciences, vol. 11, pp. S100-S104, 2011. 


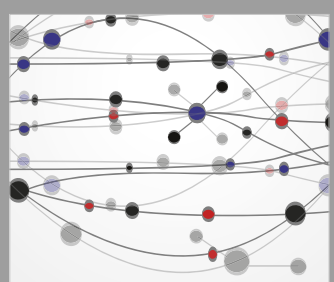

The Scientific World Journal
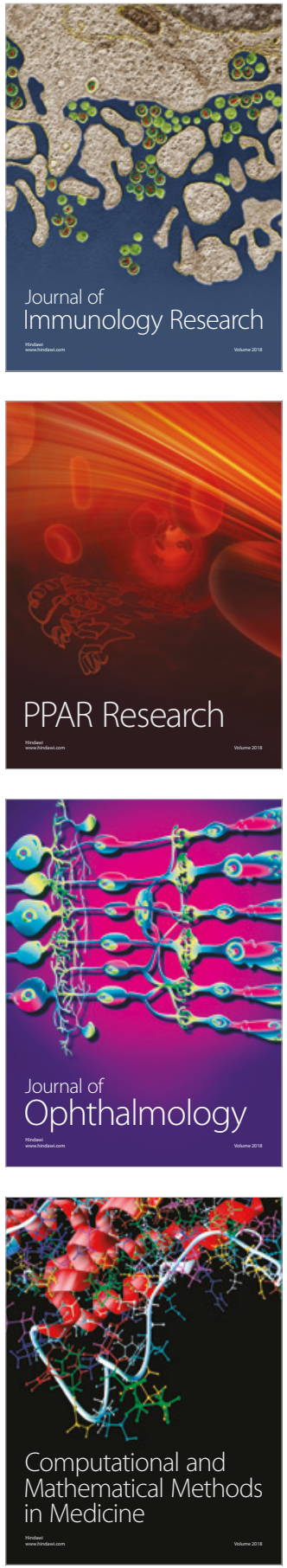

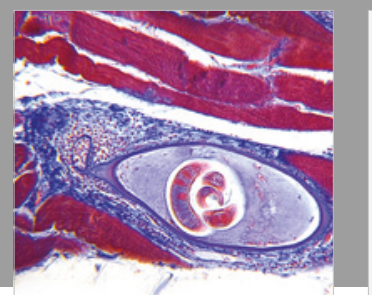

Gastroenterology Research and Practice

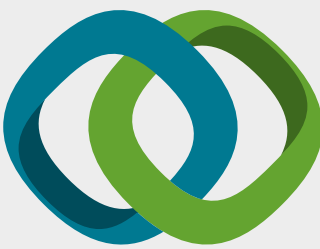

\section{Hindawi}

Submit your manuscripts at

www.hindawi.com
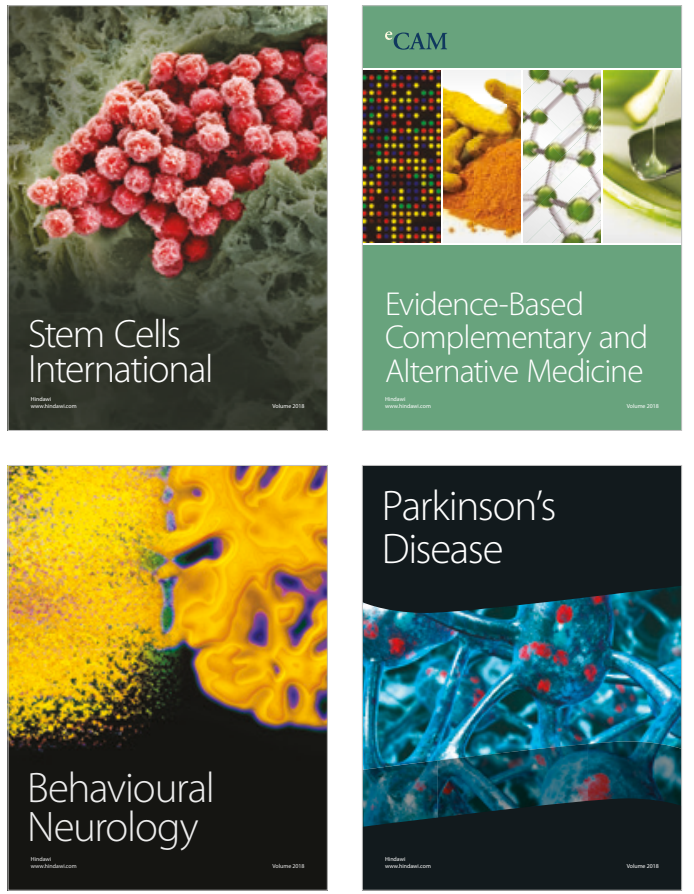

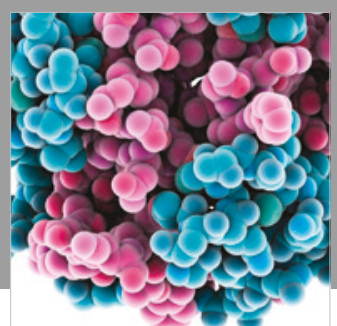

ournal of

Diabetes Research

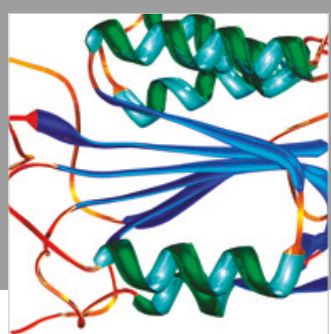

Disease Markers
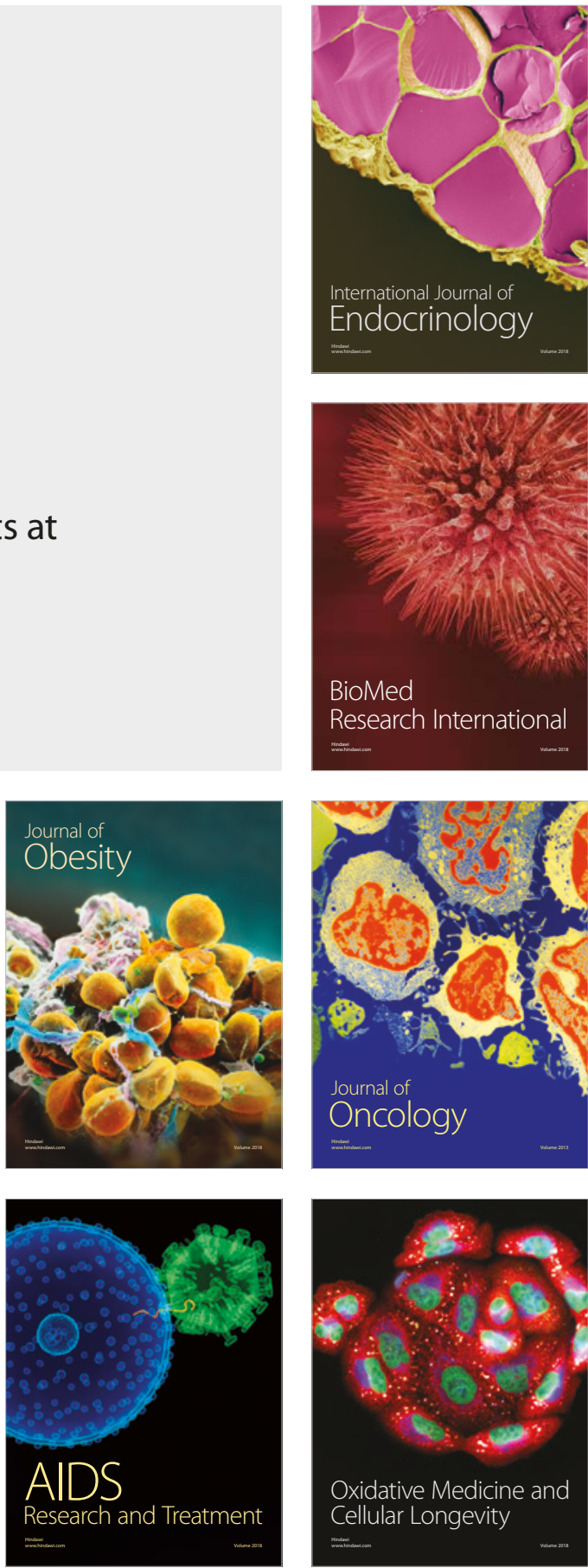